Table 1.

\begin{tabular}{lccc}
\hline & Overall & PMR & PMR+GCA \\
\hline $\mathrm{n}(\%)$ & 243 & $178(73.3)$ & $65(26.7)$ \\
Female sex (\%) & $146(60.1)$ & $98(55.1)$ & $48(73.8)$ \\
Shoulder girdle pain (\%) & $236(97.1)$ & $174(97.8)$ & $62(95.4)$ \\
Pelvic girdle pain (\%) & $174(71.6)$ & $127(71.3)$ & $47(72.3)$ \\
Inflammatory back pain (\%) & & & \\
No & $107(44.0)$ & $83(46.6)$ & $24(36.9)$ \\
Yes & $106(43.6)$ & $70(39.3)$ & $36(55.4)$ \\
Lower limb pain (\%) & & & \\
No & $87(35.8)$ & $61(34.3)$ & $26(40.0)$ \\
Yes & $81(33.3)$ & $68(38.2)$ & $13(20.0)$ \\
Weight loss (\%) & $112(46.1)$ & $78(43.8)$ & $34(52.3)$ \\
CRP (mg/l) (median [IQR]) & $46.0[19.0,77.7]$ & $44.0[16.9,74.2]$ & $52.0[27.9,85.0]$ \\
ESR (mm/h) (mean (SD)) & $65.2(30.3)$ & $62.7(30.2)$ & $72.3(29.7)$ \\
Hemoglobin (g/dl) (mean (SD)) & $12.1(1.5)$ & $12.2(1.5)$ & $11.7(1.6)$ \\
Thrombocytes (1e+09/ml) (mean (SD)) & $341.9(106.3)$ & $323.9(103.2)$ & $375.8(104.6)$ \\
\hline
\end{tabular}

In the univariable analyses the following factors were most strongly associated with vasculitic PET findings: female sex (OR 2.31, Cl 1.17-4.58), inflammatory back pain (OR 2.73, $\mathrm{Cl}$ 1.32-5.64), temperature $>37^{\circ}$ (OR 1.83, $\mathrm{Cl}$ 0.90-3.7), weight loss (OR 1.83, $\mathrm{Cl}$ 0.96-3.51), thrombocytosis (i.e., patients with a thrombocyte count $1 \mathrm{SD}$ above mean have an $\mathrm{OR}$ of 1.51, Cl 1.05-2.18), anemia (i.e., $1 \mathrm{~g} / \mathrm{dl}$ decrease in $\mathrm{Hb}$ below mean corresponds to an OR of 1.25, $\mathrm{Cl} 1.00-1.56$ ). Patients with lower limb pain were less likely to have vasculitis ( $\mathrm{OR} 0.43, \mathrm{Cl} 0.19$ 0.95). The estimated ORs were very similar in the multivariable model although the $95 \% \mathrm{Cls}$ became wider.

Conclusion: Although the prevalence across published studies showed substantial variation, 6 out of 13 studies reported a prevalence of silent GCA in $18-40 \%$ of all PMR patients. The exploratory analysis of the collected IPD identified female sex, inflammatory back pain, fever, weight loss, absence of lower leg pain, thrombocytosis and anemia as factors associated with LV-GCA. These findings should be validated in future prospective cohort studies. The presence or absence of these factors may further aid in diagnosing LV-GCA in PMR patients. REFERENCES:

[1] Buttgereit F, Dejaco C, Matteson EL, Dasgupta B. Polymyalgia Rheumatica and Giant Cell Arteritis: A Systematic Review. JAMA. 2016 Jun 14;315(22):2442-58.

Acknowledgements: The study is funded by the "Schweizerische Stiftung für die Erforschung der Muskelkrankheiten (SSEM)".

Disclosure of Interests: Daniele Silvio Gozzoli: None declared, Andrea Hemmig: None declared, Lars Hemkens: None declared, Laura Werlen: None declared, Hannah Ewald: None declared, Christoph Berger: None declared, Diego Kyburz Grant/research support from: DK reports personal fees from Abbvie, Gilead, Lilly, Novartis and Pfizer, outside of the submitted work, Stephan Imfeld: None declared, Markus Aschwanden: None declared, Mihaela Stegert: None declared, Dario Camellino: None declared, Marco Amedeo Cimmino: None declared, Corrado Campochiaro Grant/research support from: personal fees from Roche, Alessandro Tomelleri: None declared, Liesbet Henckaerts: None declared, Daniel Blockmans Speakers bureau: Paid speaker for Roche, Consultant of: Paid consultant for Roche, Patricia Moya: None declared, Hector Corominas: None declared, Russell Buchanan: None declared, Claire Owen Speakers bureau: $\mathrm{CO}$ has received speaking honoraria from Roche, Janssen, Novartis and Pfizer, and meeting sponsorship from Roche, UCB and Janssen, Yannick van Sleen: None declared, Elisabeth Brouwer Speakers bureau: E. Brouwer as an employee of the UMCG received speaker fees and consulting fees from Roche in 2017, 2018 which were paid to the UMCG, Consultant of: E. Brouwer as an employee of the UMCG received speaker fees and consulting fees from Roche in 2017, 2018 which were paid to the UMCG, Hiroyuki Ymashita: None declared, Thomas Daikeler: None declared

DOI: 10.1136/annrheumdis-2021-eular.1803

\section{POS0807 RETINAL VESSEL CALIBERS AS A NON-INVASIVE BIOMARKER OF INFLAMMATORY BURDEN IN PRIMARY SYSTEMIC VASCULITIS}

O. Argyropoulou ${ }^{1}$, E. Aissopou ${ }^{1}$, A. Argyris ${ }^{1}$, A. Goules ${ }^{1}$, C. Mavragani ${ }^{2}$, N. Tentolouris ${ }^{3}$, P. Sfikakis ${ }^{3}$, P. Vlachoyiannopoulos ${ }^{1}$, A. Tzioufas ${ }^{1}$ A. Protogerou'. ' ${ }^{1}$ School of Medicine, National and Kapodistrian University of Athens, Pathophysiology, Athens, Greece; ${ }^{2}$ School of Medicine, National and Kapodistrian University of Athens, Physiology, Athens, Greece; ${ }^{3}$ Medical School, National and Kapodistrian University of Athens, Athens, First Department of Propaedeutic Internal Medicine, Athens, Greece

Background: Primary Systemic Vasculitides (PSV) constitute a heterogeneous group of rare and potentially life-threatening autoimmune diseases, characterized by a varying degree of inflammatory response, leading to local or generalized vascular disease. Vessel involvement accounts for the micro- and macrovascular complications of the disease, along with the classic risk factors including, among others age and chronic use of steroids (1). Early identification of high-risk patients for cardiovascular disease (CVD) development and the contribution of inflammation towards this adverse outcome are still unmet needs. Alterations of retinal microcirculation have been independently associated with increased CVD risk in the general population (2). The potential changes of retinal vasculature and their association with disease activity and the magnitude of inflammation have not been studied in PSV so far.

Objectives: To explore the effect of disease activity and inflammation on retinal microcirculation in PSV, classified according to vessel size as large, medium or small vessel vasculitides (LVV, MVV or SVV respectively), and polymyalgia rheumatica (PMR) without vasculitis.

Methods: Fifty-nine patients, 43 with active disease [30 active vasculitis (12 LVV, $4 \mathrm{MVV}, 14$ SVV) and $13 \mathrm{PMR}$ ] and 16 with chronic inactive disease (13 vasculitis 3 PMR) were studied. All patients were matched at 1:1 ratio with 59 controls, without underlying autoimmune/autoinflammatory disorder, neoplasia or infection, according to age, gender, CVD history, BMI, smoking, arterial hypertension, dyslipidemia, diabetes mellitus and treatment related to comorbidities. A total of 32 rheumatoid arthritis (RA) patients with mild to moderate inflammatory component as defined by standard of care acute phase reactants (ESR and CRP) and 16 chronic RA patients with normal ESR and CRP levels, matched 1:1 according to all the above parameters with 32 active and 16 inactive vasculitis/PMR patients respectively, served as disease controls. Digital retinal images were obtained and retinal vessel calibers were measured with a validated software to determine central retinal arteriolar and venular equivalents ratio (CRAE and CRVE respectively). For 16 patients with active vasculitis/PMR, retinal examination was performed in two time points (baseline and $\leq 6$ months later).

Results: In the overall population, patients with active Vasculitis/PMR had increased CRVE $(213.8 \pm 21.7$ vs $201.3 \pm 17.1, p<0.001)$ and CRAE $(180.0 \pm 19.2$ vs $164.1 \pm 17.5 p<0.001)$ compared to healthy controls. Separating patients according to disease type, we found that in LVV, MVV and PMR, CRAE $(p \leq 0.05)$ and CRVE $(p<0.05)$ were increased compared to control group, while in SVV only CRAE was increased $(p<0.001)$. Interestingly, chronic patients with disease in remission displayed higher CRAE compared to matched controls $(179.8 \pm 17.2$ vs $169.1 \pm 11.1, p=0.006)$. After immunosuppressive treatment for $\leq 6$ months CRVE and to a lesser extent CRAE were reduced ( $p=0.048$ and 0.149 respectively) with a stronger statistical significance found in the Vasculitis group $(p=0.026$ and 0.069 respectively). Pearson's linear correlation coefficient in active disease state (a baseline examination) revealed positive bivariate correlation only between CRVE with ESR and CRP. Patients with Vasculitis/PMR had also increased CRAE when compared to RA patients in both active and inactive disease status $(182.8 \pm 19.4 \mathrm{vs}$ $170.1 \pm 18.4, p<0.001$ and $179.8 \pm 17.2$ vs $166.3 \pm 17.9, p=0.005$ respectively).

Conclusion: Systemic inflammation alters retinal microcirculation in both a reversible (venules) and irreversible (arterioles) way, independently of PSV form. Thus, common disease specific pathogenetic mechanisms related to inflammation may be implicated in vascular remodeling. Sequential follow-up of PSV patients will address whether retinal vessel calibers may serve as a biomarker of disease activity and CVD development.

REFERENCES:

[1] Argyropoulou OD et al. Curr Opin Rheumatol 2017.

[2] Shaohua G et al. Current Atherosclerosis reports 2020.

Disclosure of Interests: None declared

DOI: 10.1136/annrheumdis-2021-eular.1950

\section{POS0808 CHARACTERISTICS OF GIANT CELL ARTERITIS FLARES AFTER SUCCESSFUL TREATMENT WITH TOCILIZUMAB: RESULTS FROM THE LONG-TERM EXTENSION OF A RANDOMIZED CONTROLLED PHASE 3 TRIAL}

S. Unizony ${ }^{1}$, S. Mohan ${ }^{2}$, J. Han ${ }^{2}$, J. H. Stone ${ }^{1} .{ }^{1}$ Harvard Medical School, Massachusetts General Hospital Rheumatology Unit, Boston, United States of America; ${ }^{2}$ Genentech, US Medical Affairs, South San Francisco, United States of America

Background: GiACTA investigated tocilizumab (TCZ) for the treatment of gian cell arteritis (GCA).

Objectives: To investigate disease flare characteristics after successful treatment with TCZ in GiACTA.

Methods: We report a post hoc analysis from part 2 of GiACTA. Part 1 was a 52-week, double-blind, randomized controlled period and part 2 was a 2-year open-label follow-up. In part 1, patients received TCZ $162 \mathrm{mg}$ subcutaneously every week or every other week with a 26-week prednisone taper or placebo plus a 26- or 52-week prednisone taper. Patients who were in remission at week 52 were to enter part 2 on no TCZ treatment. Part 2 treatment was at the inves tigator's discretion. We report characteristics of first disease flare in patients assigned to TCZ in part 1 who were in sustained remission at week 52 and experienced flare in part 2 . Flare was defined as reappearance of cranial symptoms (headaches, jaw claudication, visual manifestations, scalp tenderness) or polymyalgia rheumatica (PMR) symptoms or elevation of erythrocyte sedimentation rate $(E S R) \geq 30 \mathrm{~mm} / \mathrm{h}$ attributable to $\mathrm{GCA}$ that required treatment. 
Results: Of 149 patients assigned to TCZ in part 1, $81(54 \%)$ were in sustained remission on entering part 2. Of these 81 patients, $37(46 \%)$ experienced at least one flare in part 2, including 17 with new-onset GCA and 20 with relapsing GCA at baseline. Median time to flare was 26.6 weeks. In patients with new-onset GCA, flares included cranial (53\%) more often than PMR symptoms (18\%). Cranial and PMR symptoms were balanced (both $60 \%$ ) at the time of flare in patients with relapsing GCA. Visual manifestations occurred in two patients (5\%) (Table 1). ESR and CRP were elevated in $65 \%$ and $36 \%$ of patients, respectively, at the time of flare. Three (8\%) flares occurred with elevated ESR without clinical symptoms.

Table 1. Clinical manifestations during flare in part 2

Part 1 Treatment

TCZ QW+Pred TCZ Q2W+Pred AllTCZ

New-onset disease

Patients, $n$

Patients with $\geq 1$ flare, $n(\%)^{b}$

\section{8}

14

42

Patients with ESR $\geq 30 \mathrm{~mm} / \mathrm{h}$ during flare, $\mathrm{n}(\%)^{\mathrm{b}}$

$6(66.7)$

$8(57.1)$

$(40.5)$

$(40.5)$

12
$70.6)$

Patients with GCA signs or symptoms during

flare, $\mathrm{n}(\%)^{\mathrm{c}}$

PMR symptoms

Cranial symptoms

Amaurosis fugax

Blurred vision

Diplopia

Blindness

Ischemic optic neuropathy

Fever

Other ${ }^{\mathrm{e}}$

Relapsing disease

Patients, $\mathrm{n}$

Patients with $\geq 1$ flare, $n(\%)^{b}$

$4(44.4)$
$7(77.8)$

$6(75.0)$

$7(77.8)$

2 (25.0)

6 (35.3)

14
$(82.4)$
$3(17.6)$

$4(44.4) \quad 5(62.5) \quad 9(52.9)$

0

1 (11.1)

0

0

0
$1(11.1)$

3 (33.3)

0

0

0

$\begin{array}{cc}0 & 0 \\ 0 & 1(5.9) \\ 2(25.0) & 5(29.4)\end{array}$

28

28
$14(50.0)$

11

Patients with $E S R \geq 30 \mathrm{~mm} / \mathrm{h}$ during flare, $\mathrm{n}(\%)^{\mathrm{b}}$

8 (57.1)

6 (54.5)

39

20

12

$(60.0)$

Patients with $\mathrm{CRP} \geq 10 \mathrm{mg} / \mathrm{L}$ during flare, $\mathrm{n}(\%)^{\mathrm{b}}$

$5(35.7)$

$4(66.7)$

Patients with GCA signs or symptoms during

flare, $\mathrm{n}(\%)^{\mathrm{c}}$

PMR symptoms

$14(100)$

$3(50.0)$

$8(40.0)$

$6(100) \quad 20(100)$

$8(57.1)$

$4(66.7)$

12

(60.0)

Cranial symptoms $^{\mathrm{d}}$

8 (57.1)

$4(66.7)$

Amaurosis fugax

Blurred vision

Diplopia

Blindness

Ischemic optic neuropathy

Fever

Other $^{\mathrm{e}}$

$1(7.1)$

0
0

0
$1(7.1)$

$1(7.1)$
0

$6(4.3)$
Patients with CRP $\geq 10 \mathrm{mg} / \mathrm{L}$ during flare, $\mathrm{n}(\%)^{\mathrm{b}}$

$1(11.1) \quad 2(25.0) \quad 3(17.6)$

$0+1(5.9)$

Denmark; ${ }^{3}$ University Medical Center Groningen, Pathology and Clinical Immunology, Groningen, Netherlands; ${ }^{4}$ Martini Ziekenhuis Groningen, Rheumatology, Groningen, Netherlands; ${ }^{5}$ Hycult Biotech, R\&D Department, Uden, Netherlands

Background: Diagnosing patients with giant cell arteritis (GCA) remains difficult. Due to its non-specific symptoms, it is challenging to identify GCA in patients presenting with polymyalgia rheumatica (PMR), which is a more common dis ease (1). In addition, commonly used acute-phase markers fail to discriminate between GCA patients and (infectious) mimicry patients.

Objectives: To investigate a selection of biomarkers for their utility in the accurate diagnosis of GCA in two cohorts.

Methods: Treatment-naïve GCA patients participated in the Aarhus GCA/PMR cohort $(\mathrm{N}=52)$ and the Groningen GPS cohort $(\mathrm{N}=48)$. Symptoms and biomarker levels were compared to patients presenting phenotypically as isolated PMR, disease controls and healthy controls ( $\mathrm{HCs}$ ). Diagnosis or exclusion of diagnosis of GCA was based on clinical assessment and in the majority of cases aided by imag ing. Serum/plasma levels of 12 biomarkers were measured by ELISA or Luminex. Results: In both the Aarhus and the GPS cohort, we found that weight loss, elevated erythrocyte sedimentation rate (ESR) and higher angiopoietin-2/-1 ratios but lower matrix metalloproteinase (MMP)-3 levels identify concomitant GCA in PMR patients (Figure 1). In addition, we confirmed (1) that elevated platelet counts are characteristic of GCA but not of GCA look-alikes, and that low MMP-3 and proteinase 3 (PR3) levels may help to discriminate GCA from other diseases (Figure 1). Multiple biomarkers of inflammation were found elevated in patient and disease control groups when compared to HCs.

Conclusion: This study, performed in two independent cohorts, consistently shows the potential of angiopoietin-2/-1 ratios and MMP-3 levels to identify GCA in patients presenting with PMR. These biomarkers may be used to select which PMR patients require further diagnostic workup. Platelet counts may be used to discriminate GCA from GCA look-alike patients.

\section{A}

\begin{tabular}{|c|c|c|c|c|c|}
\hline Study group & & & & Study group & Cut-off \\
\hline GCA/PMR overlap & high & Angpl-2/angpl-1 ratio & low & Isolated PMR & $\begin{array}{l}\text { Aarhus: } 0.048 \\
\text { GPS : } 0.051\end{array}$ \\
\hline GCA/PMR overlap & low & MMP-3 & high & Isolated PMR & $\begin{array}{l}\text { Aartus: } 23 \mathrm{ng} / \mathrm{mL} \\
\text { GPS: } 14 \mathrm{ng} / \mathrm{mL}\end{array}$ \\
\hline GCA/PMR overlap & high & ESR & low & Isolated PMR & $\begin{array}{l}\text { Aarhus: } 60 \mathrm{~mm} / \mathrm{h} \\
\text { GPS: } 91 \mathrm{~mm} /\end{array}$ \\
\hline GCA/PMR overlap & often & Weightloss & Not often, & Isolated PMR & $\begin{array}{r}\text { Aarhus } 3 \mathrm{~kg} \\
\text { GPS: } 2 \mathrm{~kg}\end{array}$ \\
\hline
\end{tabular}

B

\begin{tabular}{|c|c|c|c|c|c|}
\hline Study group & & & & Study group & Cut-off \\
\hline GCA & high & Plateletcount & low & GCA look-alike & $\begin{array}{l}\text { Aarhus: } 391 \times 10^{\circ} \\
\text { GPS: } 318 \times 10^{9}\end{array}$ \\
\hline GCA & low & MMP-3 & high & GCA look-alike & $\begin{array}{l}\text { Aarhus: } 19 \mathrm{ng} / \mathrm{mL} \\
\text { GPS: } 13 \mathrm{ng} / \mathrm{mL}\end{array}$ \\
\hline GCA & low & PR3 & high & GCA look-alike & $\begin{array}{l}\text { Aarhus: } 38 \mathrm{ng} / \mathrm{mL} \\
\text { GPS: } 66 \mathrm{ng} / \mathrm{mL}\end{array}$ \\
\hline GCA & often & Weightloss & Not often & GCA look-alike & $\begin{array}{l}\text { Aartus: } 3 \mathrm{~kg} \\
\text { GPS: } 2 \mathrm{~kg}\end{array}$ \\
\hline
\end{tabular}

Figure 1. Summary of the most important and consistent findings in both cohorts. A shows the four factors that perform best in discriminating GCA/PMR patients overlap from isolated PMR patients in both cohorts. B shows the four factors that perform best in discriminate GCA patients from GCA look-alike patients in both cohorts. Cut-off values for the biomarkers are calculated by the Youden index.

\section{REFERENCES:}

[1] van der Geest, KSM, Sandovici M, Brouwer E, Mackie SL. Diagnostic accuracy of symptoms, physical signs, and laboratory tests for giant cell arteritis: A systematic review and meta-analysis. JAMA internal medicine. 2020.

Disclosure of Interests: Yannick van Sleen: None declared, Philip Therkildsen: None declared, Annemieke Boots: None declared, Berit Dalsgaard Nlelsen: None declared, Kornelis van der Geest: None declared, Peter Heeringa: None declared, Minke G. Huitema: None declared, M.D. Posthumus: None declared, Maria Sandovici: None declared, Erik Toonen Employee of: Is an employee of Hycult Biotech, Jannik Zijlstra: None declared, Ellen-Margrethe Hauge: None declared, Elisabeth Brouwer: None declared

DOI: 10.1136/annrheumdis-2021-eular.2636

holder of: Genentech, Inc., Employee of: Genentech, Inc., John H. Stone Consultant of: Roche/Genentech and Sanofi

DOI: 10.1136/annrheumdis-2021-eular.2602

\section{POS0809 A BIOMARKER PROFILE AIDING AN EARLY DIAGNOSIS OF GIANT CELL ARTERITIS}

Y. Van Sleen ${ }^{1}$, P. Therkildsen ${ }^{2}$, A. Boots ${ }^{1}$, B. Dalsgaard Nielsen ${ }^{2}$, K. Van der Geest $^{1}$, P. Heeringa ${ }^{3}$, M. G. Huitema ${ }^{1}$, M. D. Posthumus ${ }^{4}$, M. Sandovici ${ }^{1}$, E. Toonen ${ }^{5}$, J. Zijlstra ${ }^{1}$, E. M. Hauge ${ }^{2}$, E. Brouwer ${ }^{1} .{ }^{1}$ University Medical Center Groningen, Rheumatology and Clinical Immunology, Groningen, Netherlands; ${ }^{2}$ Aarhus University Hospital, Rheumatology, Aarhus N, 